\title{
ADVANCES IN SOIL MOISTURE RETRIEVAL FROM NEAR-SURFACE MEASUREMENTS USING SATELLITE REMOTE SENSING
}

\author{
Richa Prajapati ${ }^{1,}{ }^{*}$, Debashis Chakraborty ${ }^{1}$, Vimal Kumar ${ }^{1}$ \\ ${ }^{1}$ Division of Agricultural Physics, ICAR- Indian Agricultural Research Institute, New Delhi - richaprajapati13@gmail.com
}

Commission V, SS: Natural Resources Management

KEY WORDS: Soil moisture, microwave remote sensing, optical, thermal, soil moisture proxy

\begin{abstract}
:
Soil moisture influences numerous environmental processes occurring over large spatial and temporal scales. It profoundly influences the hydrological and meteorological activity together with climate predictions and hazard analysis. Space-borne sensors are capable of retrieving the surface soil moisture over a region on a regular basis. Latent heat measurements of soil, reflectance based methods, microwave measurements and synergistic approaches are some of the techniques used since long for providing soil moisture estimates over regional and global scales. Due to the dynamic interaction of soil with crops, retrieval of surface soil moisture is always challenging. This paper gives a brief overview of advance in soil moisture retrieval techniques, and an attempt to generate surface soil moisture from fine-resolution satellite remote sensing data. The optical remote sensing explores the linear relationship between land surface reflectance and soil moisture content, and through development of empirical spectral vegetation indices. Another way to estimate soil moisture emerged by measuring amplitude of diurnal temperature, which is closely related to thermal conductivity and heat capacity of soil. Emergence of radiometric satellite measurements at fine resolution has reached at a higher level of technology these days. Microwave remote sensing techniques have a long legacy of providing surface soil moisture estimates with reasonable accuracy. The SMOS (Soil Moisture and Ocean Salinity) and SMAP (Soil Moisture Passive and Active) missions launched in 2009 and 2015 respectively, are completely dedicated for providing soil moisture at global scale with a spatial resolution of $35 \mathrm{~km} \& 3-40 \mathrm{~km}$. These soil moisture products, however, provides data at highly coarser spatial resolution. The launch of Sentinels gave insight by providing active radar and optical data at higher resolution $(\sim 10 \mathrm{~m})$. Sentinel-1 is the first SAR (Synthetic Aperture Radar) constellation having 6-day revisit time providing data in C-band with dual polarisations. However, no algorithm or methodology is available to generate surface soil moisture product at a finer resolution from dual polarisations. Sentinel-1 data has been used to generate regional surface soil moisture image through modelling. The same has been also used for generating surface soil moisture map of IARI farm at New Delhi. Dubois, a bare surface model, was tested for its suitability for surface soil moisture retrieval of the farm. In addition, radar- based Soil moisture (SM) proxy method was used over Sentinel-1 data for the month of July 2018, and validated through actual surface soil moisture (gravimetric) measurements. Results were satisfactory for a range of 4-16 $\mathrm{m}^{3} \mathrm{~m}^{-3}$ of soil moisture, with coefficient of determination $\left(\mathrm{R}^{2}\right)$ as 0.45 , RMSE of 2.35 and a p-value of 0.005 . However, over a higher range of soil moisture (21-33 $\mathrm{m}^{3} \mathrm{~m}^{-3}$ ), which occurred after the rainfall, the $\mathrm{R}^{2}$ value reduced to 0.22 with larger RMSE. Results suggested that SM-proxy approach might work well for a limited range (drier part) of soil moisture content, and not for the wet soil.
\end{abstract}

\section{INRODUCTION}

Soil moisture plays a major role in climate-change projections and controls numerous processes such as water, energy and biogeochemical cycles. The alterations in soil moisture (SM) availability are a cumulative result of change in climatic conditions, which is a key issue for agriculture. It is defined as "the amount of water stored in the spaces (pores) between soil particles in the unsaturated soil zone, also termed the vadose zone" (Liang, Li, \& Wang, 2012). Surface SM refers to the water content within the upper $5 \mathrm{~cm}$ of soil. Also it is termed as the fraction of water by volume held in the soil against gravity. Global SM is approximately $0.05 \%$ of Earth's total volume of water, yet it plays a major role in controlling the exchanges of energy and matter (Schneider, Root, \& Mastrandrea, 1996). Distribution of SM in terms of spatial and temporal scale plays a crucial role in Earth's climate regimes. Soil moisture controls the separation of precipitation into infiltration and runoff, where infiltration regulates the availability of water for vegetation growth and runoff strongly impacts the rate of surface erosion and other river processes. It also monitors the partition of incoming solar radiation into latent and sensible heat exchange in the atmosphere (Entekhabi, Rodriguez-Iturbe, \& Castelli, 1996). The SM information is very essential for various commercial and government organisations concerned with flood control, climate and weather change, drought monitoring, irrigation scheduling, runoff potential, soil erosion and crop yield forecasting. Hence, a reliable and accurate estimate of soil moisture is essential for numerous applications and makes it an indispensable variable for terrestrial research (Hawley, Jackson, \& Mccuen, 1983).

In 1960s, SM studies originated based on experiments and empirical relationships and in 1970s it was being considered as an important surface parameter in addition to other variables. Primarily in 1978 , it was found that due to unique thermal properties and large heat capacity of water, it was possible to remotely sense the moisture content in the top layer of the soil. High dielectric constant of water as compared to dry soil at microwave frequency made emissivity of soils as strong function of moisture. In addition to remote sensing techniques in-situ measurements and soil water models were also used to determine surface SM (Schmugge, Jackson, \& McKim, 1980). In-situ measurements being labour intensive and time consuming could not be performed on larger study areas. Hence, with the advent of sensor functionality and improved spatial and temporal image resolution, remote sensing facilitated data collection over large area at repeated and short time intervals. The sensors measure electromagnetic energy reflected 
or emitted from the earth surface in different wavelengths and the measured signal should then be related to soil moisture through mathematical modelling (Troch, Troch, SU, \& Lin, 1990). Various researchers showed that surface SM can be estimated using optical, thermal infrared as well as passive and active microwave remote sensing. The fundamental difference among these is different source of electromagnetic energy, properties observed by the sensor and physical relationship between sensed property and SM content (Jeffrey Phillip Walker, 1999). Remote sensing sensors can be mounted over airborne as well as satellite based platforms. Earlier many airborne acquisitions were performed for collecting data over a specific region using active and passive microwave sensors for example PALS (Passive and Active L and S- Band Radiometer) used in 2002 (Hasan, Montzka, Bogena, Rudiger, \& Vereecken, 2012). However, there is a need for temporal continuity and global coverage in SM measurements hence satellite remote sensing is advantageous.

\section{SOIL MOISTURE MEASUREMENT TECHNIQUES: REMOTE SENSING BASED}

$\mathrm{SM}$ as a process occurring at an interface between land surface and the Earth's atmosphere frequently changes in space and time. It is a variable parameter and many factors governs its spatial variability such as soil type, topography, vegetation cover, climate, soil texture and land use. In temporal domain, variation can be found in order of few hours in the uppermost centimetres of a soil profile. Precipitation is found to be the main driving force for the changes in the spatio-temporal SM patterns. There are two techniques for measuring soil moisture content a) point based measurements and b) remote sensing methods. The approaches to measure SM are broadly classified as; Gravimetric method, electromagnetic based method, nuclear based, tensiometric method, hygrometric and others (Petropoulos, Griffiths, Dorigo, Xaver, \& Gruber, 2013). This study focuses on various satellite remote sensing methods to estimate soil moisture.

\subsection{Optical remote sensing method}

The solar domain having wavelengths between 04-2.5 $\mu \mathrm{m}$, measures the reflected radiation of sun after interaction from the Earth's surface. Many experiments were performed since long to explore the relationship between SM and reflectance. In 1925, Angstrom's found that reflectance reduced after the wetness of soil increases. He explained this phenomenon" by the total internal reflection on the water film covering the soil particles" (Angstrom, 1925). Thereafter many researchers reported similar observations and proposed various empirical relationships between soil surface reflectance and its moisture (Bowers \& Hanks, 1965; Bowers \& Smith, 1972; Dalal \& Henry, 1986). The methods to derive SM using visible infrared band can be divided into two categories a) Single spectral analysis method and $b$ ) vegetation index method. The first method is based on the fact that reflectance of water absorption bands is entirely different from non-absorption bands. Absorption amplitude was found to be linearly related to moisture content at water absorption bands. Experiments showed that at low moisture levels, reflectance decreases with increasing moisture content while at higher moisture levels reflectance increases. Jackson et al. experimentally found that albedo of dry soils was two times greater than that of wet soils (Jackson, Idso, \& Reginato, 1976). Also, empirical approaches could not produce good results for regions outside the calibration conditions due to variation in organic matter, mineral composition, soil roughness and its texture. These disadvantages led to development of physical models to analyse the correlation of soil reflectance at different moisture conditions. These models were based on physical laws such as Beer's law and were capable to capture both scattering and absorption effects of SM. Further with the advent of monitoring instruments, few models took into account surface roughness, viewing angle and other soil spectral characteristics. Soil reflectance models were evaluated with different methods such as: relative reflectivity method, derivative/difference method and discrete band difference method (Weidong et al., 2003). This method was capable to obtain reasonable results but for specific soil types only because soil attributes changes significantly from site to site.

The second method is based on the fact that soil reflectance is affected by vegetation conditions under water stress. Hence various indices have been proposed to detect drought conditions such as NDVI (Normalised Difference Vegetation Index). The comparison of vegetation index at different times gives an estimate of drought. Some classical drought indices such as Vegetation Condition Index (VCI) and Anomaly Vegetation Index (AVI) were formulated taking NDVI as main criteria (Chen Weiying, Xiao Qianguang, \& Sheng Yongwei, 1994; Kogan, 1995). VCI described spatio-temporal variations, vegetation cover and impacts of weather on vegetation while AVI was used widely to study vegetation dynamics annually. To derive SM the relationship with various water absorption bands was explored. Gao, developed Normalised Difference Water Index (NDWI) utilizing the reflectance at $1.24 \mu \mathrm{m}$ as it is more sensitive to SM (Gao, 1996). The pattern observed in the spectral signatures due to variations in soil moisture was formulated using Perpendicular Drought Index (PDI). It produced much credible results as compared to previous approaches. However these methods are time-consuming as a long period is required to record the real time SM status. Also index method does not take in account the effect of temperature and rainfall. Therefore, direct measure of soil moisture using soil reflectance, for a large area is highly constrained but it has proven its potential in combination with Radiative temperature measurements.

\subsection{Thermal remote sensing method}

Thermal band operates in the wavelength region of 3 to $14 \mu \mathrm{m}$. Soil moisture estimation using thermal infrared band of the electromagnetic spectrum is based on the principle that objects having temperature above $0 \mathrm{~K}$ emits electromagnetic energy at all wavelengths. This thermal emission capability of all landscape features such as vegetation, soil, water etc. lays the foundation of SM measurements (Jensen, 2007). There are different thermal properties of soil and water that differentiates them, example thermal conductivity, thermal inertia and heat capacity. Thus detection of these properties helps to measure minor changes in SM using established methods and models. Areas having higher soil moisture are warmer at night and cooler during the day time (Griend \& Engman, 1985). The radiation emitted from the earth's surface also depends upon the soil surface emissivity which can be assumed or empirically determined when models are used (Ottlé \& Vidal-Madjar, 1994). External factors such as low penetration capability of thermal band, presence of vegetation on ground, high perturbation of signals by clouds, attenuation of signals by atmosphere are to be taken care of. In 1979, Pratt and Ellyett claimed that if there is a presence of dense canopy of vegetation cover which obscures about $10-20 \%$ of soil surface then thermal 
emission cannot record the radiation temperature from earth's surface (Pratt \& Ellyett, 1979). Data is ideally collected around midday to accentuate changes in thermal properties between dry and moist soils.

Literatures defined two main methods named as Thermal Inertia and Temperature Index used for SM estimation. Thermal inertia (TI) is a physical property which characterizes the surface resistance to temperature change. Many studies claim that increase in soil water content is directly proportional to increase in TI and hence reducing the diurnal temperature (Minacapilli, Iovino, \& Blanda, 2009; Verhoef, 2004). Mathematically this relation is defined as: $\mathrm{TI}=\sqrt{ } \lambda \rho \mathrm{C}$

where $\lambda=$ soil thermal conductivity $\left(\mathrm{W} \mathrm{m}^{-1} \mathrm{~K}^{-1}\right)$

$\rho=$ soil bulk density $\left(\mathrm{kg} \mathrm{m}^{-3}\right)$

$\mathrm{C}=$ soil heat capacity $\left(\mathrm{J} \mathrm{kg}^{-1} \mathrm{~K}^{-1}\right)$

$\mathrm{C}$ can be expressed in the form of soil bulk density in dry and solid phase and volumetric soil water content.

Direct measurements of TI is not accessible using remote sensing techniques but it offers a way to estimate the same by detecting land surface temperature differences at day-night or sunset-sunrise. Idso et al. in 1976 proposed a simple model to derive soil thermal inertia using surface daily temperatures and soil heat flux (Idso, Jackson, \& Reginato, 1976). Studies show that TI method was applicable for bare and dry ground, to avoid complexity but in later years research revealed that moisture estimates can be done over partially vegetated soil (Maltese, Capodici, Ciraolo, \& La Loggia, 2013; Price, 1985). The multispectral imagery is used to derive apparent thermal inertia (ATI) by making measurements of surface albedo and temperature difference. Further remote sensing methods were combined with physical parameters of soil for estimation of SM. Overall TI methods have physical base and require clear day and night images that are difficult to obtain. Also vegetation obscures soil information thus this method is only applicable for sparsely vegetated or bare fields.

The second method Temperature Index method has a basic principle that land surface temperature for bare soil is temperature recorded from the soil surface and that from vegetated field is canopy temperature. If there is an increase in the latter then it indicates vegetation is subject to water stress thus indicating that LST can be used to monitor SM. McVicar et al. developed Normalised Difference Temperature Index (NDTI) that was very similar to SM and reflects the spatialtemporal variations of moisture content (McVicar, Jupp, Yang, \& Tian, 1992). Many studies claim that Temperature/Vegetation Index (VI) method can provide soil moisture information using LST and VI feature space.

\subsection{Microwave remote sensing methods}

For about four decades microwave remote sensing has evolved as an important tool that expedites soil moisture estimation on regional and global scales. It is considered as a primary technique to retrieve SM and measures the electromagnetic radiation in the wavelength range of $0.5-100 \mathrm{~cm}$. The theory behind this method is based on the fact that a large contrast exists between dielectric properties of water $(\sim 80)$ and dry soil $(\sim 4)$. Hence wet soil has an increases dielectric constant $(\sim 35)$ that increases with increase in moisture content and is detectable through microwave sensors. These dielectric properties affect both emissivity and backscattering properties in microwave region thus making it possible to retrieve SM using satellite measurements. It involves two techniques: Active and Passive. The former measures the backscattered or reflected power from the surface and passive microwave observe the natural microwave emissions. Generally $\mathrm{L}, \mathrm{C}$ and $\mathrm{X}$ bands are considered to be sensitive for SM estimation with $\mathrm{L}$ band having a higher penetrating capability than $\mathrm{X}$ band.

\subsubsection{Passive microwave remote sensing method}

Since 1970's passive microwave sensors were recognised as the greatest utility to measure soil moisture and hence wide range of sensors were used. These include Scanning Multichannel Microwave Radiometer (SMMR) (1978-1987), Special Sensor Microwave Imager (SSM/I) (1987-2007), WindSAT mission (2003-2012), Advanced Microwave Scanning Radiometer Earth Observing System (AMSR-E) (2002-2011) with two SM dedicated missions as Soil Moisture Ocean Salinity (SMOS) and Soil Moisture Active Passive (SMAP). Passive sensors measure the self-emitted or reflected radiations from the Earth's surface that are characterised by brightness temperature that are characterised by brightness temperature $(\mathrm{Tb})$.

\subsubsection{Active microwave remote sensing method}

Active microwave sensors emit radar pulses towards the ground by the use of radar antenna (real or synthetic) and receive signals that carry information of target. They are capable to provide SM at higher spatial resolution as compared to passive sensors. However surface roughness plays a major role which is not a serious limitation for passive sensors. Various sensor configurations and different surface parameters gave rise to the development of numerous backscattering models over past three decades. These are categorised as Theoretical, Empirical and Semi-empirical models with an additional techniques called change detection approach. An overview of these models is provided in the following sub-sections.

Physical model/Theoretical based model: Physical based model simulates the backscattering coefficient derived from application of the theory of electromagnetic wave scattering from a randomly rough conducting surface and express the simulated backscatter coefficient as a function of soil dielectric constant, surface roughness and sensor characteristics. It is based on analytical solutions of the integral equations for tangential surface fields and accounts for both single and multiple surface diffusion phenomena (Fung, Li, \& Chen, 1992). These models can be applied to wide range of roughness scale (N. Baghdadi et al., 2004) and have different ranges of validity, depending on the wavelength and surface roughness. The different physical models are: Kirchhoff Approximation (KA) consisting of Geometric Optics Model and physical Optics model, small perturbation model (SPM), Small Slope Approximation (SSA), Michigan Microwave Canopy Scattering (MIMICS) and Integral Equation model (IEM) (Karthikeyan, Pan, Wanders, Kumar, \& Wood, 2017). Among them, IEM is the most widely used due to its wide range of roughness conditions ( $\mathrm{k} . \mathrm{rms} \leq 3, \mathrm{k}$ is wave number $\& \mathrm{rms}$ is root mean square surface height) and formulated by Fung in 1992. The IEM is shown to unite the Small Perturbation model at low frequency and the Kirchhoff model at high frequency and therefore it is applicable to a wide range of roughness conditions or frequencies (Su, Troch, \& De Troch, 1997). This model can predict the generic trend of backscattering coefficient in response to changes in soil moisture content in a more appropriate manner, however these includes a complex mathematical equations for the parameterization of soil and vegetation surface. Due to its complexity the approximate solutions of IEM model are usually used in applications. Advanced IEM model is used widely in various studies with divergent SM retrieval accuracy (N. Baghdadi, Holah, \& Zribi, 
2006; Nicolas Baghdadi, Zribi, Loumagne, Ansart, \& Anguela, 2008).

Empirical Models: These models require little physics equations and provide a description about effect of surface roughness and soil moisture on the backscattering coefficient by mean of regression analysis. These are generally derived from great number of experimental or in situ measurements to establish statistical and empirical relationships for inversion of soil moisture from backscattering observations (Jeffrey $\mathrm{P}$. Walker, Houser, \& Willgoose, 2004). Traditionally, some known in-situ soil moisture measurements and corresponding radar backscattering coefficients were used to calibrate a simple form of the equation to predict unknown soil moisture. These models are site specific, may not applied to datasets other than those used for development and are mostly only valid in certain regions of roughness, frequency, incidence angle and soil moisture content (Dubois \& Engman, 1995). The main advantage of empirical backscattering models over theoretical backscattering models is that many natural surfaces do not fall into the validity regions of the theoretical backscattering models, and even when they do, the available backscattering models fail to provide results in good agreement with experimental observations (Oh, Sarabandi, \& Ulaby, 1992). These models were developed based on $\mathrm{L}, \mathrm{C}$ and $\mathrm{X}$ band scatterometer data and cover the ranges for surface roughness and moisture content as: $0.1<\mathrm{ks}<0.6$ and $0.09<\mathrm{m}_{\mathrm{v}}<0.31$. These models yield often accurate soil moisture results but sometimes are not applicable for datasets that lie outside the given calibration conditions. Another disadvantage of this method is that large in-situ data is required which is a challenging and costly issue.

Semi-empirical models: Semi-empirical backscattering models are an improvement to empirical backscattering models and are the intermediate between the theoretical and the empirical models. These models use simulated data from a theoretical backscattering model for deriving empirical backscattering models that describes the backscattering response for a wide range of surface conditions. These models have the conceptual background of physical models overlaid with simulations or experimental studies that help in simplification of the models (Karthekeyan et al., 2017). The advantages of such kind of models is that they are not site dependent (as in the case of empirical models), and can also be applied when little or no information about the surface roughness is available (Baghdadi et al., 2008). Two most commonly used semi empirical models are Oh model and Dubois model.

Oh model relates the ratios of backscattering coefficients in separate polarizations to volumetric SMC and surface roughness. Dubois model developed using ground measurements with scatterometter data taking multiple frequencies in $\mathrm{L}, \mathrm{C}, \mathrm{X}$ band in $\mathrm{HH}$ and $\mathrm{VV}$ polarization with incidence angle ranging from $30^{\circ}$ to $60^{\circ}$. It developed a relationship between two co-polarized backscattering coefficient of bare soil surface as a function of rms height, dielectric constant, incidence angle and frequency. Some studies report coupling of the both the methods naming it as SemiEmpirical Coupled model (SEC) (Capodici, Maltese, Ciraolo, La Loggia, \& D’Urso, 2013).

Change Detection Approach: In this method it is assumed that surface roughness and vegetation condition remains invariant or varies on a much longer scale as compared to the soil moisture.
Thus tracking the changes in the radar backscatter in repeat passes is accounted to soil moisture. It is an attractive technique as it is simple and provides an indirect way to account surface roughness effects and heterogeneity of land cover. Several change detection approaches have been developed so far for the soil moisture retrieval. The temporal image differencing method involve the estimation of Normalized backscattering Moisture index (NBMI) which calculates the relative soil moisture values ranging from 0 to 1 using the backscatter coefficients response at two different times (Shoshany et al., 2000). Researchers have categorized these techniques into three groups: differencing, principal component analysis (PCA) and interferometric coherence. A through description if these can be found in Barrett et al., 2009 (Barrett, Dwyer, \& Whelan, 2009). It was found that full polarimetric data provides structural information about the target and proves that coherence information is very beneficial for SM retrieval (BourgeauChavez, Leblon, Charbonneau, \& Buckley, 2013).

\section{STUDY AREA AND SATELLITE DATA}

\subsection{Study area}

The experiment to estimate soil moisture using microwave remote sensing data was carried over Indian Agricultural Research Institute (IARI) farm located at New Delhi as shown in the figure. IARI campus covers an area of about 500 hectares with agricultural farms where different crops such as rice, wheat, maize, mustard, barley etc. are sown and experimented for different varieties. The temperature in summer season varies from $34-40^{\circ} \mathrm{C}$ and in winters from $8-11^{\circ} \mathrm{C}$.

\subsection{Satellite data and field data sampling}

Sentinel-1A is used here which provides data freely with temporal resolution of 12 days all over India. The specifications are given in the table.

\begin{tabular}{|l|l|l|}
\hline S.No & Parameters & Specifications \\
\hline 1. & Launch date & April 3, 2014 \\
\hline 2. & Orbital Altitude & $693 \mathrm{Km}$ \\
\hline 3. & Sensor band & C-Band \\
\hline 4. & Central frequency & $5.405 \mathrm{GHz}$ \\
\hline 5. & Polarisations & $\begin{array}{l}\mathrm{HH}+\mathrm{HV}, \quad \mathrm{HH}, \\
\text { VV+VH, VV }\end{array}$ \\
\hline 6. & Incidence Angle & $20^{\circ}-46^{\circ}$ \\
\hline 7. & $\begin{array}{l}\text { Interferometric } \\
\text { Wide Swath mode }\end{array}$ & $5 \mathrm{mx} 20 \mathrm{~m}$ \\
\hline \multicolumn{3}{|c|}{ Table 1 Satellite specifications } \\
\hline
\end{tabular}

In this study Sentinel-1A, Ground Range Detected (GRD) product in Interferometric Wide swath (IW) mode, was used for the month of July with VV and VH polarizations. The satellite data was available in the month of July on following dates: 2/07/2018, 14/07/2018, 18/07/2018 and 26/07/2018.

Field data was acquired contemporaneously with the satellite pass and soil samples were collected from the IARI farms over bare fields. Random sampling was performed and data from about 15-20 locations was collected. For soil moisture estimation, gravimetric method was used for calculation of moisture content. A hand held GPS receiver, Trimble GeoExplorer 2008, was used to record the accurate location in the field. 


\section{METHODOLOGY}

The satellite data collected on 4 different dates was processed using open source SNAP software (version 6.0) as provided by ESA. Dubois model was tested on the data and SM proxy method was also used. The details of methods used are described in this section.

\subsection{Satellite data processing}

The workflow is divided into many steps. Level-1 GRD product is represented in the form of amplitude values for two polarisations $\mathrm{VV}$ and $\mathrm{VH}$. The pre-processing was carried out for both the polarisations. First precise orbit files were applied to raw amplitude images. These orbit files provide correction to satellite position and velocity information is updated. The next step was to convert digital values in each polarisation into backscattering coefficients using radiometric calibration. Due to the presence of lots of speckle in the image multilooking as well as speckle filtering was performed using Refined Lee filter. The final step was to apply Range Doppler Terrain Correction for geocoding and to correct geometric distortions in the image. This terrain correction is done using SRTM Digital Elevation Model (DEM) to make geometric representation of the image close to the real world scenario. The processed data is orthorectified image with $10 \mathrm{mx} 10 \mathrm{~m}$ spatial resolution in UTM projection.

\subsection{Dubois Model}

Dubois model is one of the semi-empirical models used for SM estimation with an advantage over Oh and IEM models that the dielectric constant can be expressed as a function sensor parameters and co-polarised backscattering coefficients, hence reducing the dependency of SM on roughness parameters (Panciera, Tanase, Lowell, \& Walker, 2014). In 1995 Dubois et al. proposed this model for multiple frequency, polarisations (HH and VV), and incidence angles. It establishes a relationship between bare soil co-polarised backscattering coefficients $\left(\sigma^{\circ}\right)$, dielectric constant $(\varepsilon)$, frequency and root mean square (RMS) height (s) as shown in the equation (Dubois \& Engman, 1995):

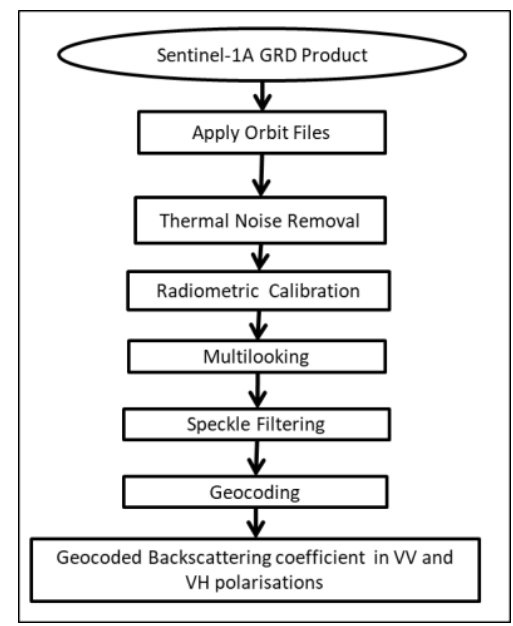

Figure 1. Methodology for processing Satellite data

$\sigma_{V V}^{o}=10^{-2.35}\left(\frac{\cos ^{3} \theta}{\sin ^{3} \theta}\right) 10^{0.046 \varepsilon \tan \theta}(k s \operatorname{Sin} \theta)^{1.1} \lambda^{0.7}$ where $\mathrm{k}$ represents the wavenumber and $\lambda$ is the wavelength. Here ks assumed to be 2.5 considering the bare soil surface with nominal roughness (Bai \& $\mathrm{He}, 2015$ ). Using this equation dielectric constant can be calculated and further using Tops model (Topp, Davis, \& Annan, 1980) volumetric soil moisture is estimated.

\subsection{SM Proxy method}

The backscatter coefficient derived from SAR data and volumetric SM is needed to be connected for SM estimation. For bare soil surfaces, SAR backscatter in VV and $\mathrm{VH}$ polarisations depends on various factors such as incidence angle, surface roughness, moisture and frequency. Another method experimented for SM retrieval is SM proxy (SMP) method which considers an approximation that a linear relationship can be defined between SM and SMP. The given equation defines this relationship as (Dobson \& Ulaby, 1986; Holah, Baghdadi, Zribi, Bruand, \& King, 2005):

$$
\begin{aligned}
& S M=S M_{\text {min }}+\left(S M_{\text {max }}-S M_{\text {min }}\right) X S M P \\
& S M P=\left(\frac{\sigma_{p p}^{o}-\sigma_{p p, \text { min }}^{o}}{\sigma_{p p, \text { max }}^{\mathrm{o}}-\sigma_{p p, \text { min }}^{\mathrm{o}}}\right)
\end{aligned}
$$

Here SMP is the function of $\sigma^{\circ}$ (backscatter), $p$ can be vertical or horizontal polarizations, $\mathrm{SM}_{\min }$ and $\mathrm{SM}_{\max }$ are maximum and minimum SM values which can be defined as:

$S M_{\text {min }}=0.15 x_{\text {clay }}, S M_{\max }=0.489-0.126 \mathrm{xf}_{\text {sand }}$

These minimum and maximum values are dependent on soil porosity where $\mathrm{SM}_{\min }$ is the residual $\mathrm{SM}$ and $\mathrm{SM}_{\max }$ is $\mathrm{SM}$ at saturation (Brisson \& Perrier, 1991; Cosby, Hornberger, Clapp, \& Ginn, 1984; Wagner, Lemoine, \& Rott, 1999).

\subsection{Gravimetric method}

It is one of the direct measures of SM and hence used widely. It determines the weight of water contained in the sample of soil relative to the weight of the dry soil in terms of percentage. This can also be expressed in terms of volume as ratio of volume to water present to the total volume of the soil sample (Reynolds, 1970). The weight of empty aluminium tin and its weight with about $10 \mathrm{gm}$ of soil sample (wet) in it are recorded. Thereafter the samples are placed in oven $105^{\circ} \mathrm{C}$ for $24-48$ hours to dry, until there is no difference between any two consecutive measurements of dry soil weight (Shukla et al., 2014).

$$
\theta_{d}=\frac{\left(W_{w}\right)-\left(W_{d}\right)}{\left(W_{d}\right)}
$$

where, $\mathrm{W}_{\mathrm{w}}=$ Weight of wet soil, $\mathrm{W}_{\mathrm{d}}=$ Weight of dry soil and $\theta_{\mathrm{d}}$ is moisture content in dry weight basis. To convert this to volumetric soil moisture it is multiplied by ratio of bulk density of soil and water. The only disadvantage of this method is that it is very labour intensive and requires lot of time. The repeated sampling also destroys the experimental area (Verstraeten, Veroustraete, \& Feyen, 2008).

\section{RESULTS AND DISCUSSION}

The Sentinel-1 data for 4 different days were downloaded was processed and converted from GRD amplitude images to speckle filtered and geocoded backscattering coefficient for 
analysis. The sigma naught images for co-polarised data for 2 July and 14July are shown in figure 2.

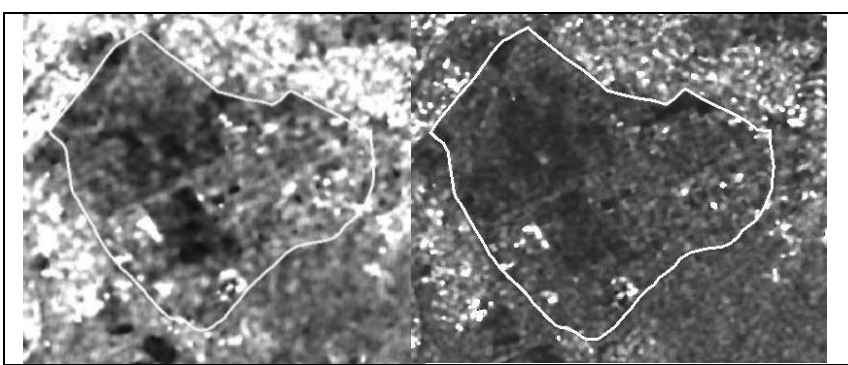

Figure 2. Sigma Naught (a) 2 $2^{\text {nd }}$ July 2018 (b) $14^{\text {th }}$ July 2018

The automatic weather station installed in the fields recorded rainfall of about $122.4 \mathrm{~mm}$ thus soil moisture increased and hence backscattered reduced giving a darker appearance in the image. Similarly on 17July and 26July rainfall of about $28.6 \mathrm{~mm}$ and $5.6 \mathrm{~mm}$ was recorded and the satellite showed similar dark patches in the farm area. Further using band math in SNAP, Dubois model was implemented for calculation of dielectric constant. It was found that the calculated values were negative hence indicating that use of this bare soil model with single copolarised data is not suitable for our study area. It can produce better results if both $\mathrm{HH}$ and VV polarisations are available.

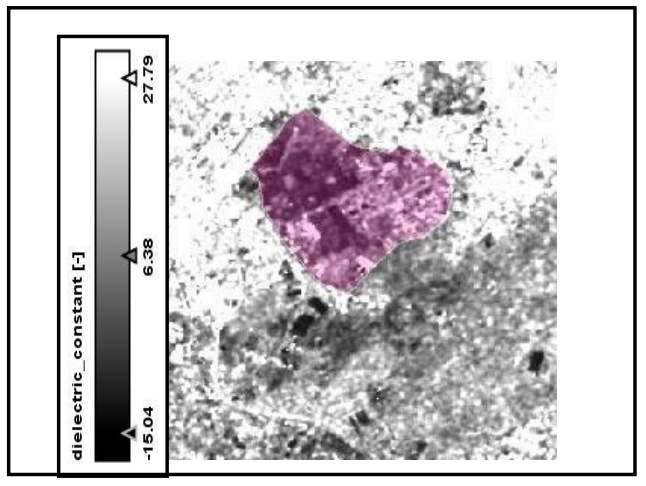

Figure 3. Dielectric constant using Dubois model

The attainment of negative dielectric constant proves that Dubois model was not suitable for SM estimation in our study area which can be due to single co polarised channel available in Sentinel -1 data. Secondly SM proxy method was experimented for our area. Using this method SMP and SM were calculated. The fraction of clay and fraction of sand was assumed as 0.27 and 0.37 respectively as extracted from other studies carried out at IARI. After deriving the backscatter coefficient the images were converted to $\mathrm{dB}$ scale and maximum and minimum values for each image, using only the farm area, was noted. These derived values were compared to the field observed values and the graphs are shown below. The variation in soil moisture for different dates as observed by satellite and that collected from field is given in table.

\begin{tabular}{|c|c|c|}
\hline $\begin{array}{c}\text { Date of } \\
\text { Observation }\end{array}$ & $\begin{array}{c}\text { Field collected SM } \\
\left(\mathrm{m}^{3} \mathrm{~m}^{-3}\right)\end{array}$ & $\begin{array}{c}\text { Satellite derived } \\
\mathrm{SM}(\mathrm{m} 3 \mathrm{~m}-3)\end{array}$ \\
\hline 2 July 2018 & $4.6-16.3$ & $5.5-15.8$ \\
\hline 14 July 2018 & $32.9-21.5$ & $9.6-17.6$ \\
\hline 18 July 2018 & $11.4-22.3$ & $5.3-12.9$ \\
\hline 26 July 2018 & $20-29.5$ & $11.6-23.1$ \\
\hline \multicolumn{3}{|c|}{ Table 2 SM Range }
\end{tabular}

The analysis was carried out the obtained results and root mean square error was calculated for each image. RMSE value for $2^{\text {nd }}$ July was 0.45 and p-value was found as 0.005 . It can be deduced from these that for SM ranging from 5-16 $\left(\mathrm{m}^{3} \mathrm{~m}^{-3}\right)$, satellite derived values show similar range and $\mathrm{p}$ - value indicates that results are significant.

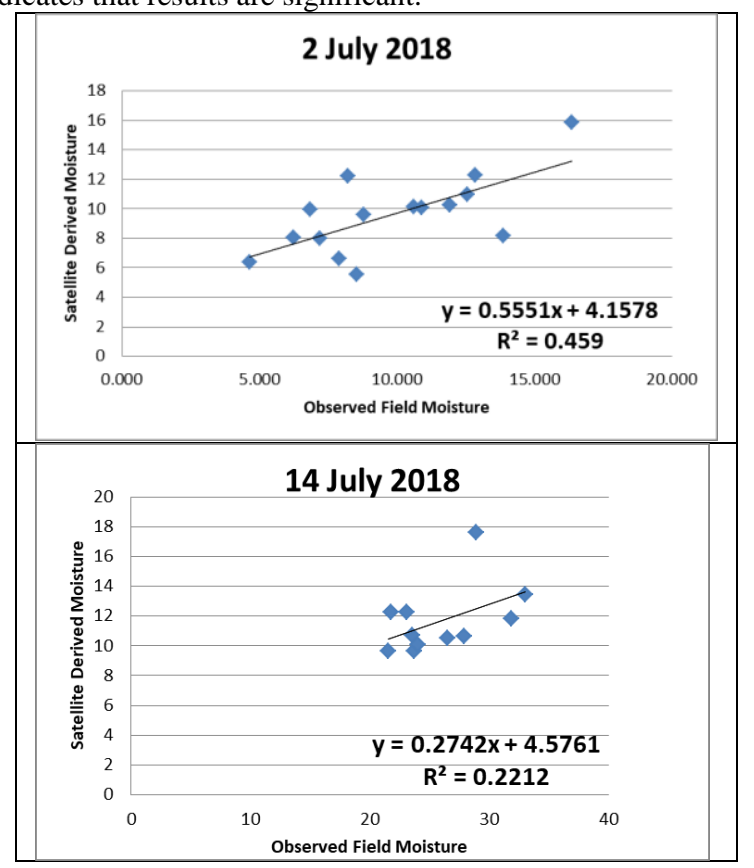

Figure 4. SM proxy method results for $2^{\text {nd }}$ of July and $14^{\text {th }}$ July 2018

But as heavy rainfall occurs on $14^{\text {th }}$ of July the moisture content increases and the corresponding satellite derived values show less correlation. Error also increases showing that this method was unable to track changes in the moisture content when the values of SM are high. Similar trend was observed for $18^{\text {th }}$ July and $26^{\text {th }}$ July as rainfall occurred near to these dates also.

\section{CONCLUSIONS}

This paper outlines the satellite based remote sensing techniques for the retrieval of soil moisture and reviews briefly the techniques in use. The soil moisture content present at the top surface can be obtained using optical, thermal and microwave remote sensing methods. However the operational products in use are made available which are derived using passive microwave methods. It is a well-established fact that numerous modelling approaches have been used in past and there modifications to form a hybrid approach is still in progress. But it is still a challenging task to retrieve moisture content with good accuracy at a regional level. The satellite data available for a specific study area and the ease to collect field observations plays a major role in selection of the technique to be used. Also deriving moisture content for bare soil is easier than that of vegetated fields as presence of crop makes it difficult to compensate for its effect and remove it to get ground moisture measures. Microwave remote sensing showed better results and is a widely adopted method over optical and thermal methods because of its all-weather penetrability and connection of soil dielectric properties to moisture. Two approaches were tested and results were analysed for bare soil fields in the month of July 2018. Dubois model gave unsatisfactory results by providing negative dielectric constant values that are not acceptable. The other method, SM proxy, proves that 
satisfactory results might be obtained for dry soil but is case of wet soil this method fails. The most promising development in SM retrieval can be made using synergistic approaches. Such approaches can address the problem encountered in discriminating the various influences on backscatter from soil moisture and other roughness or vegetation effects. The SM dedicated mission such as SMAP and SMOS provide data on a coarser level hence to develop an approach at a regional level from current available satellite data is still a challenge and yet to be explored.

\section{REFERENCES}

Angstrom, A. (1925). The albedo of various sufaces of ground. Geografiska Annaler, 7(1925), 323-342. https://doi.org/10.1080/20014422.1925.11881121

Baghdadi, N., Gherboudj, I., Zribi, M., Sahebi, M., King, C., \& Bonn, F. (2004). Semi-empirical calibration of the IEM backscattering model using radar images and moisture and roughness field measurements. International Journal of Remote Sensing, 25(18), 3593-3623. https://doi.org/10.1080/01431160310001654392

Baghdadi, N., Holah, N., \& Zribi, M. (2006). Calibration of the Integral Equation Model for SAR data in C-band and HH and VV polarizations. International Journal of Remote Sensing, 27(4), 805-816. https://doi.org/10.1080/01431160500212278

Baghdadi, N., Zribi, M., Loumagne, C., Ansart, P., \& Anguela, T. P. (2008). Analysis of TerraSAR-X data and their sensitivity to soil surface parameters over bare agricultural fields. Remote Sensing of Environment, 112(12), 4370-4379. https://doi.org/10.1016/j.rse.2008.08.004

Bai, X., \& He, B. (2015). Potential of Dubois model for soil moisture retrieval in prairie areas using SAR and optical data. International Journal of Remote Sensing, 36(22), 5737-5753. https://doi.org/10.1080/01431161.2015.1103920

Barrett, B. W., Dwyer, E., \& Whelan, P. (2009). Soil moisture retrieval from active spaceborne microwave observations: An evaluation of current techniques. Remote Sensing, 1(3), 210 242. https://doi.org/10.3390/rs1030210

Bourgeau-Chavez, L. L., Leblon, B., Charbonneau, F., \& Buckley, J. R. (2013). Evaluation of polarimetric Radarsat-2 SAR data for development of soil moisture retrieval algorithms over a chronosequence of black spruce boreal forests. Remote Sensing of Environment, 132, 71-85. https://doi.org/10.1016/j.rse.2013.01.006

Bowers, S. A., \& Hanks, R. J. (1965). Reflection of radiant energy from soils. Soil Science, 100(2), 130-138. https://doi.org/10.1097/00010694-196508000-00009

Bowers, S. A., \& Smith, S. J. (1972). Spectrophotometric Determination of Soil Water Content. Soil Science Society of America Journal, 36(6), 978-980. Retrieved from https://dl.sciencesocieties.org/publications/sssaj/abstracts/36/6/9 78

Brisson, N., \& Perrier, A. (1991). A Semiempirical Model of
Bare Soil Evaporation for Crop Simulation Models. Water Resources Research, 27(5), 719-727.

Capodici, F., Maltese, A., Ciraolo, G., La Loggia, G., \& D'Urso, G. (2013). Coupling two radar backscattering models to assess soil roughness and surface water content at farm scale. Hydrological Sciences Journal, 58(8), 1677-1689. https://doi.org/10.1080/02626667.2013.797578

Chen Weiying, Xiao Qianguang, \& Sheng Yongwei. (1994). Application of the Anomaly Vegetation Index to Monitoring Heavy Drought in 1992. Remote Sensing of Envrionment, 9(2), 106-112. Retrieved from http://en.cnki.com.cn/Article_en/CJFDTOTALYGXB402.003.htm

Cosby, B. J., Hornberger, G. M., Clapp, R. B., \& Ginn, T. R. (1984). A Statistical Exploration of the Relationships of Soil Moisture Characteristics to the Physical Properties of Soils. Water Resources Research, 20(6), 682-690. https://doi.org/10.1029/WR020i006p00682

Dalal, R. C., \& Henry, R. J. (1986). Simultaneous Determination of Moisture, Organic Carbon, and Total Nitrogen by Near Infrared Reflectance Spectrophotometry1. Soil Science Society of America Journal, 50(1), 120. https://doi.org/10.2136/sssaj1986.03615995005000010023x

Dobson, M. C., \& Ulaby, F. T. (1986). Active Microwave Soil Moisture Research. IEEE Transactions on Geoscience and Remote Sensing, GE-24(1), 23-36.

Dubois, P. C., \& Engman, T. (1995). Measuring Soil Moisture with Imaging Radars. IEEE Transactions on Geoscience and Remote Sensing, 33(4), 915-926. https://doi.org/10.1109/36.406677

Entekhabi, D., Rodriguez-Iturbe, I., \& Castelli, F. (1996). Mutual interaction of soil moisture state and atmospheric processes. Journal of Hydrology, 184(1-2), 3-17. https://doi.org/10.1016/0022-1694(95)02965-6

Fung, A. K., Li, Z., \& Chen, K. S. (1992). Backscattering from a Randomly Rough Dielectric Surface. IEEE Transactions on Geoscience and Remote Sensing, 30(2), 356-369. https://doi.org/10.1109/36.134085

Gao, B. C. (1996). NDWI - A normalized difference water index for remote sensing of vegetation liquid water from space. Remote Sensing of Environment, 58(3), 257-266. https://doi.org/10.1016/S0034-4257(96)00067-3

Griend, A. A. Van De, \& Engman, E. T. (1985). Partial Area Hydrology and Remote Sensing. Journal of Hydrology, 81, 211-251.

Hasan, S., Montzka, C., Bogena, H. R., Rudiger, C., \& Vereecken, H. (2012). Airborne passive microwave response to soil moisture: A case study for the Rur catchment. In $E G U$ Genral Assembly Conference Abstracts (Vol. 14, p. 9509).

Hawley, M. E., Jackson, T. J., \& Mccuen, R. H. (1983). SURFACE SOIL MOISTURE VARIATION ON SMALL AGRICULTURAL WATERSHEDS. Journal of Hydrology, 62, 
179-200. https://doi.org/10.1016/0022-1694(83)90102-6

Holah, N., Baghdadi, N., Zribi, M., Bruand, A., \& King, C. (2005). Potential of ASAR/ENVISAT for the characterization of soil surface parameters over bare agricultural fields. Remote $\begin{array}{lll}\text { Sensing of Environment, 96(1), 78-86. } & \text {. }\end{array}$ https://doi.org/10.1016/j.rse.2005.01.008

Idso, S. B., Jackson, R. D., \& Reginato, R. J. (1976). Compensating for Environmental Variability in the Thermal Inertia Approach to Remote Sensing of Soil Moisture. Journal of Applied Meteorology, 15(8), 811-817. https://doi.org/10.1175/1520-

0450(1976)015<0811:CFEVIT>2.0.CO;2

Jackson, R. D., Idso, S. B., \& Reginato, R. J. (1976). Calculation of evaporation rates during the transition from energy-limiting to soil-limiting phases using albedo data. Water Resources Research, 12(1), 23-26. https://doi.org/10.1029/WR012i001p00023

Jensen, J. R. (2007). Remote Sensing of the Environment: An Earth Resource perspective. Pearson Prentice Hall.

Karthikeyan, L., Pan, M., Wanders, N., Kumar, D. N., \& Wood, E. F. (2017). Four decades of microwave satellite soil moisture observations: Part 1. A review of retrieval algorithms. Advances in Water Resources, 109, 106-120. https://doi.org/10.1016/j.advwatres.2017.09.006

Kogan, F. N. (1995). Application of vegetation index and brightness temperature for drought detection. Advances in Space Research, 15(11), 91-100. https://doi.org/10.1016/02731177(95)00079-T

Liang, S., Li, X., \& Wang, J. (2012). Soil Moisture Content. In Advanced Remote Sensing (pp. 589-614). https://doi.org/10.1016/B978-0-12-385954-9.00019-8

Maltese, A., Capodici, F., Ciraolo, G., \& La Loggia, G. (2013). Mapping soil water content under sparse vegetation and changeable sky conditions: comparison of two thermal inertia approaches. Journal of Applied Remote Sensing, 7(1), 073548073548. https://doi.org/10.1117/1.JRS.7.073548

McVicar, T. R. ., Jupp, D. L. B. ., Yang, X., \& Tian, G. (1992). Linking Regional Water Balance Models with Remote Sensing. In In Proceedings of the 13th Asian Conference on Remote Sensing (p. B6). Ulaanbaatar, Mongolia.

Minacapilli, M., Iovino, M., \& Blanda, F. (2009). High resolution remote estimation of soil surface water content by a thermal inertia approach. Journal of Hydrology, 379(3-4), 229238. https://doi.org/10.1016/j.jhydrol.2009.09.055

Oh, Y., Sarabandi, K., \& Ulaby, F. T. (1992). An empirical model and an inversion technique for radar scattering from bare soil surfaces. Geoscience and Remote Sensing, IEEE $\begin{array}{llll}\text { Transactions } & \text { On, 30(2), 370-381. }\end{array}$ https://doi.org/10.1109/36.134086

Ottlé, C., \& Vidal-Madjar, D. (1994). Assimilation of soil moisture inferred from infrared remote sensing in a hydrological model over the HAPEX-MOBILHY region. Journal of
Hydrology, 158(3-4), 241-264. https://doi.org/10.1016/00221694(94)90056-6

Panciera, R., Tanase, M. A., Lowell, K., \& Walker, J. P. (2014). Evaluation of IEM, dubois, and oh radar backscatter models using airborne L-Band SAR. IEEE Transactions on Geoscience and Remote Sensing, 52(8), 4966-4979. https://doi.org/10.1109/TGRS.2013.2286203

Petropoulos, G. P., Griffiths, H. M., Dorigo, W., Xaver, A., \& Gruber, A. (2013). Surface Soil Moisture Estimation: Significance, Controls, and Conventional Measurement Techniques. In G. P. Petropoulos (Ed.), Remote Sensing of Energy Fluxes and Soil Moisture Content (pp. 29-48). Boca Raton: CRC Press.

Pratt, D. A., \& Ellyett, C. D. (1979). The thermal inertia approach to mapping of soil moisture and geology. Remote Sensing of Environment, 8(2), 151-168. https://doi.org/10.1016/0034-4257(79)90014-2

Price, J. C. (1985). On the analysis of thermal infrared imagery: The limited utility of apparent thermal inertia. Remote Sensing of Environment, 18(1), 59-73. https://doi.org/10.1016/00344257(85)90038-0

Reynolds, S. G. (1970). The gravimetric method of soil moisture determination. Journal of Hydrology, 11, 258-273.

Schmugge, T. J., Jackson, T. J., \& McKim, H. L. (1980). Survey of methods for soil moisture determination. Water Resour. Res., 16(6), 961-979. https://doi.org/10.1029/WR016i006p00961

Schneider, S. H., Root, T. L., \& Mastrandrea, M. D. (1996). Water Resources. In Encyclopedia of Climate and Weather (pp. 817-823). Oxford University Press.

Shoshany, M., Svoray, T., Svoray, T., Curran, P. J., Foody, G. M., \& Perevolotsky, A. (2000). The relationship between ERS2 SAR backscatter and soil moisture: Generalization from a humid to semi-arid transect. International Journal of Remote Sensing, 2l(11), 2337-2343. https://doi.org/10.1080/01431160050029620

Shukla, A., Panchal, H., Mishra, M., Srivastava, H. S., Patel, P., \& Shukla, A. K. (2014). Soil moisture estimation using gravimetric technique and FDR probe technique: a comparative analysis. American International Journal of Research in Formal, Applied and Natural Sciences, 8, 89-92. https://doi.org/10.1007/s11804-010-1017-2

Su, Z., Troch, P. A., \& De Troch, F. P. (1997). Remote sensing of bare surface soil moisture using EMAC/ESAR data. International Journal of Remote Sensing, 18(10), 2105-2124. https://doi.org/10.1080/014311697217783

Topp, G. C., Davis, J. L., \& Annan, A. P. (1980). Electromagnetic Determination of Soil Water Content: Measruements in Coaxial Transmission Lines. Water Resources Research, 16(3), 574-582. https://doi.org/10.1029/WR016i003p00574

Troch, F. P. DE, Troch, P. A., SU, Z., \& Lin, D. S. (1990). 
The International Archives of the Photogrammetry, Remote Sensing and Spatial Information Sciences, Volume XLII-5, 2018

ISPRS TC V Mid-term Symposium "Geospatial Technology - Pixel to People", 20-23 November 2018, Dehradun, India

Application of Remote Sensing for Hydrological Modelling. Abbott M. B. Reffsgard J.C. (Eds) Distributed Hydrological Modelling, Water Science and Technology Library, 22, 165191. Retrieved from Springer Dordrecht

Verhoef, A. (2004). Remote estimation of thermal inertia and soil heat flux for bare soil. Agricultural and Forest Meteorology, 123(3-4), 221-236. https://doi.org/10.1016/j.agrformet.2003.11.005

Verstraeten, W. W., Veroustraete, F., \& Feyen, J. (2008). Assessment of evapotranspiration and soil moisture content across different scales of observation. Sensors, 8(1), 70-117. https://doi.org/10.3390/s8010070

Wagner, W., Lemoine, G., \& Rott, H. (1999). A Method for Estimating Soil Moisture from ERS Scatterometer and Soil Data. Remote Sensing of Environment, 70(2), 191-207. https://doi.org/10.1016/S0034-4257(99)00036-X

Walker, J. P. (1999). Estimating Soil Moisture Profile Dynamics from Near-Surface Soil Moisture Measurements and Standard Meterorological. Dissertation, University of Newcastle, Australia. Retrieved from http://users.monash.edu.au/ jpwalker/thesis_pdf/preface.pdf

Walker, J. P., Houser, P. R., \& Willgoose, G. R. (2004). Active microwave remote sensing for soil moisture measurement: A field evaluation using ERS-2. Hydrological Processes, 18(11), 1975-1997. https://doi.org/10.1002/hyp.1343

Weidong, L., Baret, F., Xingfa, G., Bing, Z., Qingxi, T., \& Lanfen, Z. (2003). Evaluation of methods for soil surface moisture estimation from reflectance data. International Journal of Remote Sensing, 24(10), 2069-2083. https://doi.org/10.1016/S0034-4257(01)00347-9 